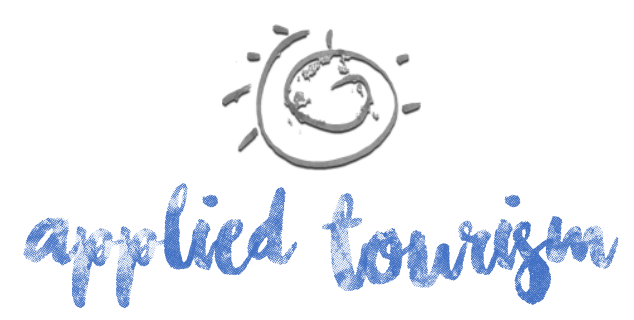

Volume 2, número 3, 2017, p. 37-64

\title{
ANÁLISE DA RELAÇÃO ENTRE DEPENDÊNCIA ECONÔMICA E PERCEPÇÃO DOS RESIDENTES SOBRE OS IMPACTOS DO DESENVOLVIMENTO TURÍSTICO DA PRAIA DA PIPA/RN
}

\author{
João Paulo Serafim Felix \\ Graduando em Gestão do Turismo \\ Instituto Federal de Educação, Ciência e Tecnologia do Rio Grande do Norte \\ joaopauloserafimfelix@gmail.com
}

Márcio Marreiro das Chagas

Doutor em Administração

Professor e Coordenador de Pesquisa e Inovação do Instituto Federal de Educação, Rio Grande do Norte

marcio.marreiro@ifrn.edu.br

Sérgio Marques Júnior

Doutor em Agronomia

Professor Titular do Programa de Pós-Graduação em Turismo da UFRN sergio@ct.ufrn.br

Victor Hugo da Silva

Mestrando em Turismo da UFRN

Victor_sector7@hotmail.com

Recebido: 28 de junho, 2017

Aprovado: 27 de outubro, 2017

\section{RESUMO}

O estudo objetiva analisar a relação entre dependência econômica e percepção dos residentes sobre o desenvolvimento turístico da Praia da Pipa/RN, um dos destinos indutores do estado. A hipótese principal é que a parcela da comunidade local que depende economicamente do turismo possui percepção mais positiva sobre os impactos da atividade, apego e imagem do local, como também apoio ao desenvolvimento turístico superior ao da parcela que não depende economicamente do setor. Para tanto, foi realizado um estudo exploratório descritivo, de abordagem analítica quantitativa, do tipo Survey, de corte transversal. A amostragem foi probabilística, com o sujeito escolhido pelo método aleatório simples. O instrumento utilizado para a coleta de dados foi um formulário baseado em escala métrica de 11 pontos, onde foram coletados 298 elementos na Praia da Pipa/RN. Os dados foram analisados por meio de estatística descritiva e teste t para amostras independentes. Dentre os resultados, foi possível confirmar a hipótese de que os residentes que dependem economicamente do turismo possuem percepções estatisticamente significativas mais favoráveis sobre os impactos no desenvolvimento do turismo do que a parcela da comunidade que não é beneficiada diretamente pelo trabalho no setor, em todas as dimensões estudadas.

Palavras-chaves: Dependência econômica; Impactos do turismo; Percepção dos residentes; Apoio do Residente. 


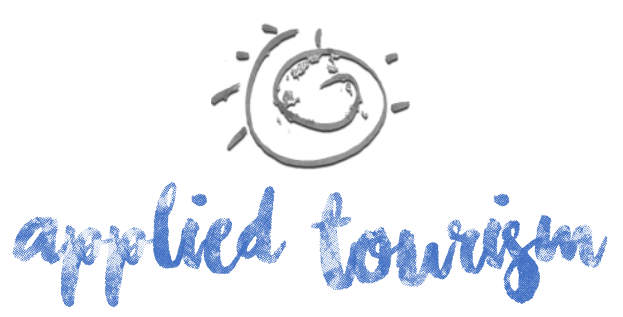

Volume 2, número 3, 2017, p. 37-64

Além disso, é possível observar que a percepção da comunidade local pode ser afetada por diversos fatores, tais como sócio demográficos. Dessa maneira, é plausível argumentar que a percepção da comunidade pode demonstrar variação a partir do gênero, da idade, tempo de moradia no local (Gursoy et al., 2004; Gursoy et al., 2010), nível de escolaridade, e, especialmente, em razão da dependência econômica do setor turístico (Haralambopoulos et al., 1996).

Nesta perspectiva, este estudo se propõe a testar a hipótese da validade estatística da variação da percepção da comunidade local sobre os impactos do turismo, apego ao local, imagem do lugar e apoio do residente em função da dependência econômica do turismo, conforme asseveram Haralambopoulos et al. (1996). Em outras palavras, este estudo se propõe a testar a hipótese que a parcela da comunidade local que depende economicamente da atividade turística possui percepção sobre o turismo (em suas dimensões de impactos positivos e negativos, apego, imagem e apoio) mais favorável que os membros da comunidade que não demonstram essa relação com a atividade. A comunidade estudada reside no destino Praia da Pipa (Tibau do Sul/RN), um dos destinos indutores do estado, nacional e internacionalmente reconhecido.

\section{REFERENCIAL TEÓRICO}

\section{Papel da Comunidade na Gestão do Turismo}

O desenvolvimento da atividade turística em uma região afeta diretamente o estilo de vida da comunidade autóctone (Jurowski, Uysal \& Williams, 1997). Nas palavras de Chagas, Marques Júnior e Silva (2016b, p. 87), a comunidade local pode ser entendida como "um todo composto por uma diversidade de outras comunidades menores que, por sua vez, atuam, exprimem e apresentam entre si significativas divergências de interesse e percepções". Em outras palavras, trata-se do ajuntamento e interação de diversos stakebolders que dão origem a um grupo de indivíduos que preservam características análogas. 


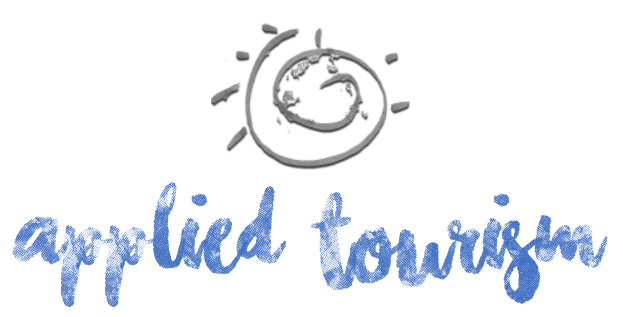

Volume 2, número 3, 2017, p. 37-64

A garantia do atendimento dos interesses dos stakebolders sobre investimentos em turismo em suas regiões são fatores essenciais para a sustentabilidade de um destino turístico, em termos de melhor eficiência na gestão da atividade, diminuição de potenciais impactos negativos (OMT, 2005a; Brandão et al., 2012; Rodrigues et al., 2014; Santos, 2014; Silva, 2014; Silva, Silva \& Chagas, 2015; Chagas et al., 2016a) e maximização dos benefícios que poderão ser destinados a comunidade local e aos próprios turistas (Scalabrini, Remoaldo \& Lourenço, 2014; Vieira, 2014).

De acordo com a OMT (2005a), o reconhecimento do papel da comunidade frente ao desenvolvimento turístico depende da integração e parceria entre os diferentes stakebolders envolvidos na busca dos objetivos propostos desde o planejamento, ao desenvolvimento e gestão da atividade turística, concepção da importância do meio ambiente pelos fornecedores e monitoramento ininterrupto da execução destes projetos. A partir destas afirmações, assevera-se que o envolvimento direto dos residentes e a garantia de seu poder de decisão sobre o desenvolvimento da atividade, elaborada e pensada dentro da realidade local do destino, demonstra ser essencial para a consolidação de um turismo que atenda aos interesses da comunidade local, visando o interesse mútuo entre as partes envolvidas neste processo.

\section{Fatores Influenciadores do Apoio do Residente ao Desenvolvimento do Turismo}

O apoio dos residentes ao desenvolvimento do turismo está fortemente ligado a percepção dos impactos sociais, culturais, econômicos e ambientais estimulados por este fenômeno, como também é afetado pelas relações de poder e confiança entre a comunidade, atores governamentais e iniciativa privada (Haralambopoulos et al., 1996; Yoon et al., 2001; Rodrigues et al., 2014; Santos, 2014; Scalabrini et al., 2014; Silva, 2014; Vieira, 2014; Silva et al., 2015), a imagem, seja afetiva e/ou cognitiva, e o apego dos residentes a localidade (Chagas et al., 2016b; Silva, Chagas \& Marques Júnior, 2016b), entre outros. Ressalta-se que as duas últimas dimensões citadas, ou seja, apego e imagem, são recentes no campo de 


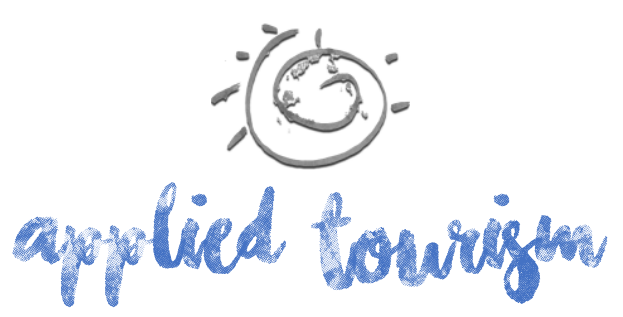

Volume 2, número 3, 2017, p. 37-64

turismo é o que remete aos ganhos econômicos; em outras palavras, é notória a absoluta predominância de interesses econômicos nesse processo (Chagas, 2008, p. 448)".

Segundo Vieira (2014), a ausência do poder público no planejamento e execução de atividades de incentivo a prática turística e de participação da comunidade local, acaba proporcionando ao autóctone a sensação de exclusão na tomada de decisão sobre desenvolvimento do turismo. Desse modo, contribuindo com incertezas quanto aos possíveis benefícios que a atividade pode estimular, prejudicando, de certa forma, o apoio, a participação e a percepção do residente sobre os benefícios gerados pelo setor de turismo.

Nesse sentido, a identificação dos fatores capazes de influenciar o apoio do residente ao desenvolvimento do turismo em uma determinada região pode estimular a elaboração de projetos turísticos mais adequados a realidade local. Além disso, o levantamento destes fatores poderá contribuir para o gerenciamento mais adequado da atividade, assim como para amenizar os potenciais conflitos entre autóctones e visitantes. Também é importante ressaltar a importância da elevação dos níveis de confiança dos residentes com relação ao turismo, atores governamentais e iniciativa privada. Este processo poderá favorecer a percepção deles quanto aos benefícios que poderão ser usufruídos no decorrer do desenvolvimento turístico.

\section{METODOLOGIA DA PESQUISA}

Essa investigação caracteriza-se como exploratória e descritiva, com abordagem analítica quantitativa, de corte transversal, caracterizada como Survey. A população deste estudo foi constituída pela comunidade local da Praia da Pipa (Tibau do Sul/RN), divididos entre os residentes economicamente dependentes do turismo e os que não estão envolvidos nas atividades produtivas do setor. A Praia da Pipa pertence ao município de Tibau do Sul/RN, e é um dos mais importantes destinos turísticos do Rio Grande do Norte e o mais importante de sua região, sendo o segundo destino indutor do estado. 


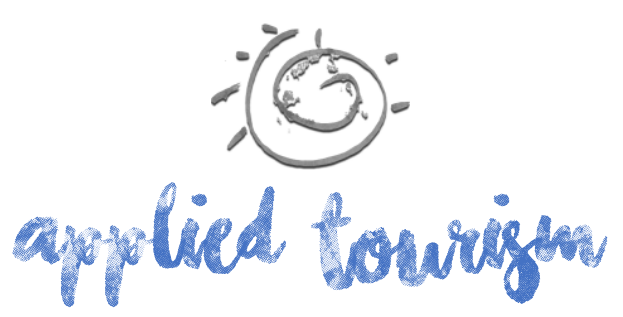

Volume 2, número 3, 2017, p. 37-64

A amostra foi obtida de modo probabilístico, pelo método aleatório simples. O número de respondentes foi calculado pela fórmula matemática sugerida, para populações finitas, pela OMT (2005b): $n=\sigma^{2 *} p^{*} q^{*} \mathrm{~N} / \mathrm{e}^{2 *}(\mathrm{~N}-1)+\sigma^{2 *}$ p*q. Em que "n" representa o tamanho da amostra, " $\sigma$ " o nível de confiança estimado em 95\% (calculado em dois desvios padrões), "p" sendo o percentual pelo qual o fenômeno é encontrado, "q" a percentagem complementar (1-p) (Hair Júnior, Black, Babin, Anderson \& Tatham, 2009), "e2" o erro máximo aplicado que foi considerado como 5\% (Corrar, Paulo \& Dias Filho, 2007). "N" constitui-se na população do local.

A coleta de dados foi desenvolvida por meio de um formulário, em escala métrica de 11 pontos, no qual [00] zero indicava total discordância e [10] dez indicava plena concordância do residente com a assertiva proposta. O formulário foi dividido em 05 blocos, com um total de 46 variáveis. As dimensões examinadas foram a percepção dos impactos positivos e negativos do turismo, apego ao lugar, imagem do destino, apoio ao desenvolvimento turístico da comunidade e as características sócio demográficas. O período da coleta de dados ocorreu entre os dias 12 de março e 01 de junho de 2016. Foram aplicados um total 298 questionários inteiramente respondidos.

As variáveis observáveis da dimensão impactos do turismo foram baseadas em Gursoy et al. (2002), Andereck et al. (2011), Yoon et al. (2001), Andereck et al. (2005), Haralambopoulos et al. (1996), Bujosa et al. (2007), Liu et al. (1986), Brunt et al. (1999), Besculides, Lee \& McCormick, (2002), Dyer et al. (2007), Saveriades (2000) e Korca (1996), as de apoio foram pautadas em Gursoy et al. (2002), Gursoy et al. (2006), Gursoy et al. (2004), Kaltenborn, Andrsen, Nellemann, Bjerke \& Thrane (2008), Nicholas, Thapa \& Ko (2009), Jones (2005) e Lepp (2007), ao passo que o apego ao lugar foi baseado em Almeida (2013), Yuksel et al. (2010), Gursoy et al. (2002), Gursoy et al. (2004), Besculides et al. (2002), Um \& Crompton (1987), Haley, Snaith \& Miller (2005) e Jurowski et al. (1997). Por último, a imagem do destino foi baseada em Chagas et al. (2016b), Martín et al. (2008), Baloglu et al. (1999), Prayag (2010), Prayag et al. (2011) e Chagas (2008). O Quadro 01 resume as hipóteses propostas. 


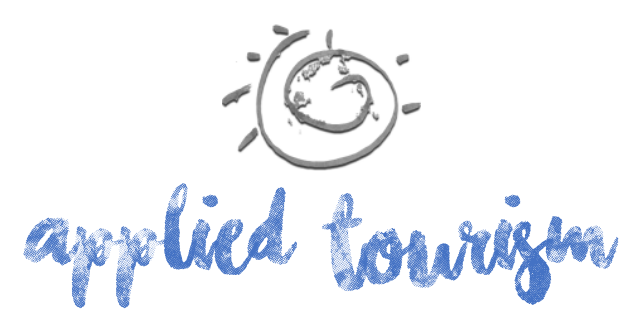

Volume 2, número 3, 2017, p. 37-64

QUADRO 01: Hipóteses do estudo.

\begin{tabular}{c||l}
\hline \hline & \multicolumn{1}{c}{ Hipóteses do Estudo } \\
\hline \hline H1 & $\begin{array}{l}\text { Os residentes com dependência econômica do turismo possuem percepção da imagem do } \\
\text { Iugar superior àqueles que não possuem dependência }\end{array}$ \\
\hline \hline H2 & $\begin{array}{l}\text { Os residentes com dependência econômica do turismo possuem percepção sobre os impactos } \\
\text { positivos do turismo mais favorável que àqueles que não possuem dependência }\end{array}$ \\
\hline \hline H3 & $\begin{array}{l}\text { Os residentes com dependência econômica do turismo possuem percepção sobre os impactos } \\
\text { negativos do turismo mais atenuada que àqueles que não possuem dependência }\end{array}$ \\
\hline \hline H4 & $\begin{array}{l}\text { Os residentes com dependência econômica do turismo demonstram maior sentimento de } \\
\text { apego à comunidade se comparados àqueles que não possuem dependência }\end{array}$ \\
\hline \hline H5 & $\begin{array}{l}\text { Os residentes com dependência econômica do turismo demonstram maior tendência de apoiar } \\
\text { o desenvolvimento da atividade turística se comparados àqueles que não possuem } \\
\text { dependência }\end{array}$ \\
\hline \hline
\end{tabular}

Fonte: autores, 2016.

Os dados foram processados por meio do Statistical Package for Social Science (SPSS v. 22.0), utilizando-se estatísticas descritivas e teste t para amostras independentes. Suprir.

Este último teste citado, é definido por Hair Júnior, Black, Babin, Anderson \& Tatham (2009, p. 274) como um método que "avalia a significância estatística da diferença entre duas médias de amostras independentes". No caso deste estudo, visa examinar se a diferença de percepção dos residentes que dependem e os não possuem dependência econômica do turismo sobre a atividade é estatisticamente significativa, ou seja, ainda de acordo com os mesmos autores "a estatística t representa a diferença de grupos em termos de erro padrão" (Hair Júnior, Black, Babin, Anderson \& Tatham, 2009, p. 275), uma vez que é calculada pela diferença entre as médias dividida pelo erro padrão.

\section{DISCUSSÃO DOS RESULTADOS}

\section{Validação da amostra}

A amostra foi composta predominantemente pelo gênero feminino (54,70\%), tendo o masculino apresentado o percentual de 45,30\%. O estado civil dominante pertence a categoria de casados (51,34\%), seguido por solteiros (23,83\%), divorciados (18,79\%), viúvos 


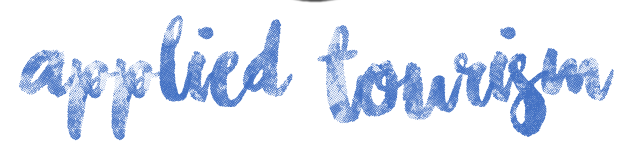

Volume 2, número 3, 2017, p. 37-64

Tabela 01: Percepção da comunidade local sobre a imagem do destino

\begin{tabular}{|c|c|c|c|c|c|c|c|}
\hline Variável & $\begin{array}{l}\text { Dependência econômica do } \\
\text { turismo }\end{array}$ & Média & $\begin{array}{l}\text { Desvio } \\
\text { padrão }\end{array}$ & $\begin{array}{l}\text { Erro padrão da } \\
\text { média }\end{array}$ & Teste $\mathrm{t}$ & $d f$ & Sig. \\
\hline \multirow[b]{2}{*}{ Eu acho Pipa um lugar bonito } & Depende economicamente & 8,80 & 1,157 & 0,086 & \multirow[b]{2}{*}{4,574} & \multirow[b]{2}{*}{277} & \multirow[b]{2}{*}{$<0,00001$} \\
\hline & $\begin{array}{c}\text { Não depende } \\
\text { economicamente }\end{array}$ & 8,07 & 1,431 & 0,146 & & & \\
\hline \multirow[b]{2}{*}{ Eu acho que Pipa tem um clima agradável } & Depende economicamente & 8,72 & 1,255 & 0,093 & \multirow[b]{2}{*}{4,365} & \multirow[b]{2}{*}{160,775} & \multirow[b]{2}{*}{$<0,00001$} \\
\hline & $\begin{array}{c}\text { Não depende } \\
\text { economicamente }\end{array}$ & 7,92 & 1,560 & 0,159 & & & \\
\hline \multirow[b]{2}{*}{ Eu acho que Pipa possui uma bela arquitetura } & Depende economicamente & 7,02 & 1,586 & 0,117 & \multirow[b]{2}{*}{2,639} & \multirow[b]{2}{*}{144,355} & \multirow[b]{2}{*}{0,00900} \\
\hline & $\begin{array}{c}\text { Não depende } \\
\text { economicamente }\end{array}$ & 6,33 & 2,283 & 0,233 & & & \\
\hline \multirow[b]{2}{*}{ Eu acho que Pipa tem lugares interessantes } & Depende economicamente & 7,38 & 1,838 & 0,136 & \multirow[b]{2}{*}{3,592} & \multirow[b]{2}{*}{146,875} & \multirow[b]{2}{*}{$<0,00001$} \\
\hline & $\begin{array}{c}\text { Não depende } \\
\text { economicamente }\end{array}$ & 6,31 & 2,581 & 0,263 & & & \\
\hline \multirow{2}{*}{$\begin{array}{l}\text { Eu acredito que Pipa possui uma prefeitura que atua de forma } \\
\text { efetiva }\end{array}$} & Depende economicamente & 2,72 & 1,400 & 0,104 & \multirow[b]{2}{*}{$-0,565$} & \multirow[b]{2}{*}{277} & \multirow[b]{2}{*}{0,57300} \\
\hline & $\begin{array}{c}\text { Não depende } \\
\text { economicamente }\end{array}$ & 2,82 & 1,480 & 0,151 & & & \\
\hline \multirow{2}{*}{$\begin{array}{l}\text { Eu acredito que Pipa possui serviços públicos que atendem às } \\
\text { necessidades dos moradores locais }\end{array}$} & Depende economicamente & 3,55 & 1,550 & 0,115 & \multirow[b]{2}{*}{176,234} & \multirow[b]{2}{*}{157,022} & \multirow[b]{2}{*}{0,86400} \\
\hline & $\begin{array}{c}\text { Não depende } \\
\text { economicamente }\end{array}$ & 3,51 & 1,723 & 0,176 & & & \\
\hline
\end{tabular}




\section{apylied owrigh}

Volume 2, número 3, 2017, p. 37-64

\begin{tabular}{|c|c|c|c|c|c|c|c|}
\hline \multirow[b]{2}{*}{ Eu acredito que Pipa oferece boas oportunidades de emprego } & Depende economicamente & 6,13 & 1,677 & 0,124 & \multirow[b]{2}{*}{4,496} & \multirow[b]{2}{*}{164,526} & \multirow[b]{2}{*}{$<0,00001$} \\
\hline & $\begin{array}{c}\text { Não depende } \\
\text { economicamente }\end{array}$ & 5,04 & 2,026 & 0,207 & & & \\
\hline \multirow[b]{2}{*}{ Eu acredito que Pipa possui um bom sistema de transporte público } & Depende economicamente & 3,43 & 1,364 & 0,101 & \multirow[b]{2}{*}{1,221} & \multirow[b]{2}{*}{183,872} & \multirow[b]{2}{*}{0,22400} \\
\hline & $\begin{array}{l}\text { Não depende } \\
\text { economicamente }\end{array}$ & 3,21 & 1,443 & 0,147 & & & \\
\hline \multirow[b]{2}{*}{ Eu acho que Pipa possui bons restaurantes } & Depende economicamente & 7,45 & 1,609 & 0,119 & \multirow[b]{2}{*}{2,221} & \multirow[b]{2}{*}{277} & \multirow[b]{2}{*}{0,02700} \\
\hline & $\begin{array}{l}\text { Não depende } \\
\text { economicamente }\end{array}$ & 6,95 & 2,134 & 0,218 & & & \\
\hline \multirow[b]{2}{*}{ Eu acho que Pipa possui uma vida noturna badalada } & Depende economicamente & 5,27 & 1,661 & 0,123 & \multirow[b]{2}{*}{$-0,067$} & \multirow[b]{2}{*}{202,307} & \multirow[b]{2}{*}{0,94700} \\
\hline & $\begin{array}{c}\text { Não depende } \\
\text { economicamente }\end{array}$ & 5,28 & 1,574 & 0,161 & & & \\
\hline \multirow[b]{2}{*}{ Eu considero que Pipa tem boas opções de lazer } & Depende economicamente & 6,58 & 1,885 & 0,139 & \multirow[b]{2}{*}{3,035} & \multirow[b]{2}{*}{174,057} & \multirow[b]{2}{*}{0,00300} \\
\hline & $\begin{array}{l}\text { Não depende } \\
\text { economicamente }\end{array}$ & 5,80 & 2,126 & 0,217 & & & \\
\hline \multirow[b]{2}{*}{ Eu acho que Pipa possui uma população amigável } & Depende economicamente & 7,64 & 1,785 & 0,132 & \multirow[b]{2}{*}{2,029} & \multirow[b]{2}{*}{277} & \multirow[b]{2}{*}{0,04300} \\
\hline & $\begin{array}{l}\text { Não depende } \\
\text { economicamente }\end{array}$ & 7,13 & 2,385 & 0,243 & & & \\
\hline \multirow[b]{2}{*}{ Eu considero Pipa um lugar seguro para morar } & Depende economicamente & 6,05 & 1,633 & 0,121 & \multirow[b]{2}{*}{2,224} & \multirow[b]{2}{*}{176,086} & \multirow[b]{2}{*}{0,02700} \\
\hline & $\begin{array}{l}\text { Não depende } \\
\text { economicamente }\end{array}$ & 5,56 & 1,817 & 0,185 & & & \\
\hline
\end{tabular}




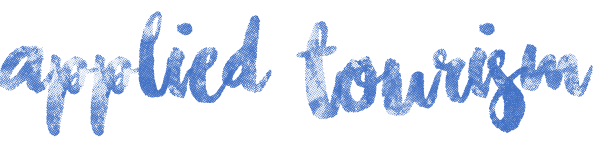

Volume 2, número 3, 2017, p. 37-64

\begin{tabular}{|c|c|c|c|c|c|c|c|}
\hline & Depende economicamente & 6,48 & 1,589 & 0,117 & & & \\
\hline Eu acho que Pipa é um lugar limpo & $\begin{array}{c}\text { Não depende } \\
\text { economicamente }\end{array}$ & 5,78 & 1,831 & 0,187 & 3,312 & 277 & 0,00100 \\
\hline
\end{tabular}

Fonte: Dados do estudo, 2016. 


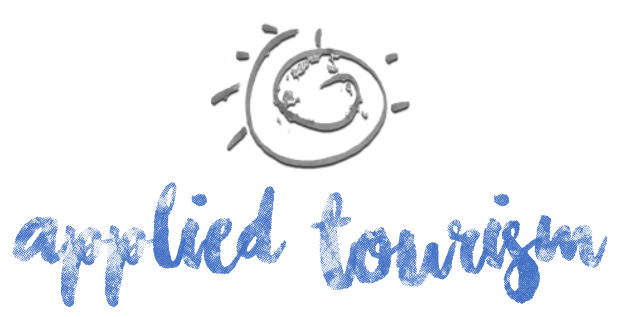

Volume 2, número 3, 2017, p. 37-64

Da tabela 01, é possível concluir que os residentes que dependem economicamente da atividade turística demonstram percepções mais favoráveis sobre a imagem do destino que o outro grupo analisado. Nesta dimensão, a diferença de percepções entre grupos foi estatisticamente significativa, com exceção de 04 variáveis, sendo 03 delas relacionadas a gestão pública do turismo, nas quais as percepções dos residentes parecem fluir para a mesma avaliação, ou seja, pelos resultados fica demonstrado acentuada insatisfação com a qualidade dos serviços públicos oferecidos. Quanto as demais variáveis, conforme já mencionado, demonstram que há diferença entre as percepções entre os grupos estudados, como pode ser visto a partir da significância estatística (Sig.) com valor inferior a 0,05, indicado pelo grifo em negrito.

\section{Percepção da comunidade local sobre os impactos positivos do turismo}

Além da imagem, foi pedido a comunidade local para avaliar os impactos positivos estimulados pelo desenvolvimento turístico. Para isso, foram elencados 08 impactos encontrados na literatura que pudessem ser avaliados pelos residentes. De um modo geral, é possível observar que os moradores que dependem economicamente da atividade turística demonstram percepção sobre os impactos positivos do turismo superior aos que não dependem. Esses resultados são demonstrados na Tabela 02, a seguir. 


\section{applied towrighen}

Volume 2, número 3, 2017, p. 37-64

Tabela 02: Percepção da comunidade sobre os impactos positivos do turismo.

\begin{tabular}{|c|c|c|c|c|c|c|c|}
\hline Variável & $\begin{array}{l}\text { Dependência econômica do } \\
\text { turismo }\end{array}$ & Média & $\begin{array}{l}\text { Desvio } \\
\text { padrão }\end{array}$ & $\begin{array}{l}\text { Erro padrão } \\
\text { da média }\end{array}$ & Teste $\mathrm{t}$ & $d f$ & Sig. \\
\hline \multirow{2}{*}{$\begin{array}{l}\text { Eu acredito que o turismo traz ou } \\
\text { promove o aumento de renda para a } \\
\text { comunidade local }\end{array}$} & Depende economicamente & 8,12 & 1,699 & 0,126 & \multirow[b]{2}{*}{3,866} & \multirow[b]{2}{*}{135,385} & \multirow[b]{2}{*}{$<0,00001$} \\
\hline & Não depende economicamente & 6,95 & 2,704 & 0,276 & & & \\
\hline \multirow{2}{*}{$\begin{array}{l}\text { Eu acredito que o turismo diversifica a } \\
\text { economia local }\end{array}$} & Depende economicamente & 8,20 & 1,737 & 0,128 & \multirow{2}{*}{3,892} & \multirow{2}{*}{136,176} & \multirow{2}{*}{$<0,00001$} \\
\hline & Não depende economicamente & 7,00 & 2,738 & 0,279 & & & \\
\hline \multirow{2}{*}{$\begin{array}{l}\text { Eu acredito que o turismo } \\
\text { cria/promove oportunidades de } \\
\text { emprego }\end{array}$} & Depende economicamente & 8,10 & 1,700 & 0,126 & \multirow[b]{2}{*}{4,175} & \multirow[b]{2}{*}{137,205} & \multirow[b]{2}{*}{$<0,00001$} \\
\hline & Não depende economicamente & 6,85 & 2,648 & 0,270 & & & \\
\hline \multirow{2}{*}{$\begin{array}{l}\text { Eu acredito que o turismo aumenta o } \\
\text { padrão de vida da população local }\end{array}$} & Depende economicamente & 8,48 & 1,687 & 0,125 & \multirow{2}{*}{4,012} & \multirow{2}{*}{143,986} & \multirow{2}{*}{$<0,00001$} \\
\hline & Não depende economicamente & 7,36 & 2,437 & 0,249 & & & \\
\hline \multirow{2}{*}{$\begin{array}{l}\text { Eu acredito que o turismo promove o } \\
\text { aumento da disponibilidade de } \\
\text { espaços de lazer e recreação }\end{array}$} & Depende economicamente & 6,57 & 1,900 & 0,140 & \multirow[b]{2}{*}{0,879} & \multirow[b]{2}{*}{157,022} & \multirow[b]{2}{*}{0,38100} \\
\hline & Não depende economicamente & 6,32 & 2,434 & 0,248 & & & \\
\hline \multirow{2}{*}{$\begin{array}{l}\text { O turismo tem estimulado variadas } \\
\text { atividades culturais promovidas pelos } \\
\text { residentes de Pipa }\end{array}$} & Depende economicamente & 6,76 & 1,871 & 0,138 & \multirow[b]{2}{*}{1,721} & \multirow[b]{2}{*}{155,459} & \multirow[b]{2}{*}{0,08700} \\
\hline & Não depende economicamente & 6,27 & 2,430 & 0,248 & & & \\
\hline \multirow{2}{*}{$\begin{array}{l}\text { Para mim, o turismo deu a } \\
\text { oportunidade de conhecer pessoas de } \\
\text { diferentes culturas }\end{array}$} & Depende economicamente & 8,20 & 1,889 & 0,140 & \multirow[b]{2}{*}{3,914} & \multirow[b]{2}{*}{137,196} & \multirow[b]{2}{*}{$<0,00001$} \\
\hline & Não depende economicamente & 6,91 & 2,430 & 0,300 & & & \\
\hline \multirow{2}{*}{$\begin{array}{l}\text { Eu acredito que o turismo ajuda na } \\
\text { preservação dos recursos naturais da } \\
\text { Pipa. }\end{array}$} & Depende economicamente & 6,20 & 1,821 & 0,135 & \multirow[b]{2}{*}{3,757} & \multirow[b]{2}{*}{168,460} & \multirow[b]{2}{*}{$<0,00001$} \\
\hline & Não depende economicamente & 5,24 & 2,136 & 0,218 & & & \\
\hline
\end{tabular}

Fonte: Dados do estudo, 2016. 


\section{aprotied towighen}

Volume 2, número 3, 2017, p. 37-64

Tabela 03: Percepção da comunidade sobre os impactos negativos do turismo

\begin{tabular}{|c|c|c|c|c|c|c|c|}
\hline Variável & $\begin{array}{c}\text { Dependência econômica do } \\
\text { turismo }\end{array}$ & Média & $\begin{array}{l}\text { Desvio } \\
\text { padrão }\end{array}$ & $\begin{array}{l}\text { Erro padrão } \\
\text { da média }\end{array}$ & Teste $\mathrm{t}$ & df & Sig. \\
\hline \multirow{2}{*}{$\begin{array}{l}\text { Eu acredito que o turismo } \\
\text { estimula o aumento dos preços } \\
\text { dos imóveis locais }\end{array}$} & Depende economicamente & 9,09 & 1,126 & 0,141 & \multirow[b]{2}{*}{0,272} & \multirow{2}{*}{218,094} & \multirow{2}{*}{0,78600} \\
\hline & $\begin{array}{c}\text { Não depende } \\
\text { economicamente }\end{array}$ & 9,05 & 0,977 & 0,215 & & & \\
\hline \multirow{2}{*}{$\begin{array}{l}\text { Eu acredito que o turismo } \\
\text { estimula o aumento dos preços } \\
\text { dos produtos e serviços } \\
\text { comercializados na Pipa }\end{array}$} & Depende economicamente & 8,94 & 1,105 & 0,141 & \multirow[b]{2}{*}{$-1,039$} & \multirow[b]{2}{*}{217,060} & \multirow[b]{2}{*}{0,30000} \\
\hline & $\begin{array}{c}\text { Não depende } \\
\text { economicamente }\end{array}$ & 9,07 & 0,965 & 0,198 & & & \\
\hline \multirow{2}{*}{$\begin{array}{l}\text { Eu vejo que a atividade turística } \\
\text { afetou negativamente o modo } \\
\text { de vida da população local }\end{array}$} & Depende economicamente & 3,39 & 1,912 & 0,141 & \multirow[b]{2}{*}{$-3,367$} & \multirow[b]{2}{*}{177,418} & \multirow[b]{2}{*}{0,00100} \\
\hline & $\begin{array}{c}\text { Não depende } \\
\text { economicamente }\end{array}$ & 4,26 & 2,109 & 0,215 & & & \\
\hline \multirow{2}{*}{$\begin{array}{l}\text { Eu acredito que o crescimento } \\
\text { do turismo aumenta a taxa de } \\
\text { criminalidade em Pipa }\end{array}$} & Depende economicamente & 6,78 & 1,909 & 0,141 & \multirow{2}{*}{$-4,502$} & \multirow{2}{*}{190,625} & \multirow{2}{*}{$<0,00001$} \\
\hline & $\begin{array}{c}\text { Não depende } \\
\text { economicamente }\end{array}$ & 7,88 & 1,937 & 0,198 & & & \\
\hline \multirow{2}{*}{$\begin{array}{l}\text { Eu acredito que o turismo } \\
\text { causou atos de vandalismo na } \\
\text { comunidade }\end{array}$} & Depende economicamente & 6,42 & 2,209 & 0,163 & \multirow[b]{2}{*}{$-4,408$} & \multirow[b]{2}{*}{277} & \multirow[b]{2}{*}{$<0,00001$} \\
\hline & $\begin{array}{c}\text { Não depende } \\
\text { economicamente }\end{array}$ & 7,66 & 2,280 & 0,233 & & & \\
\hline \multirow{2}{*}{$\begin{array}{l}\text { Eu acredito que o turismo } \\
\text { aumentou a prostituição na } \\
\text { comunidade }\end{array}$} & Depende economicamente & 6,89 & 1,979 & 0,146 & \multirow{2}{*}{$-5,294$} & \multirow{2}{*}{205,622} & \multirow{2}{*}{$<0,00001$} \\
\hline & $\begin{array}{c}\text { Não depende } \\
\text { economicamente }\end{array}$ & 8,15 & 1,841 & 0,188 & & & \\
\hline Eu vejo que o turismo aumenta & Depende economicamente & 7,66 & 1,952 & 0,146 & $-2,001$ & 99,333 & 0,04800 \\
\hline
\end{tabular}




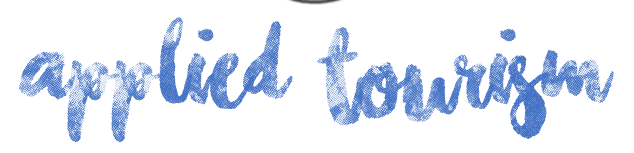

Volume 2, número 3, 2017, p. 37-64

\begin{tabular}{|c|c|c|c|c|c|c|c|}
\hline $\begin{array}{l}\text { os congestionamentos na Praia } \\
\text { da Pipa }\end{array}$ & $\begin{array}{c}\text { Não depende } \\
\text { economicamente }\end{array}$ & 9,59 & 9,385 & 0,958 & & & \\
\hline \multirow{2}{*}{$\begin{array}{l}\text { Eu acho que o turismo tem } \\
\text { contribuído para a superlotação } \\
\text { da Praia da Pipa }\end{array}$} & Depende economicamente & 7,60 & 1,898 & 0,140 & \multirow[b]{2}{*}{$-3,947$} & \multirow[b]{2}{*}{277} & \multirow[b]{2}{*}{$<0,00001$} \\
\hline & $\begin{array}{l}\text { Não depende } \\
\text { economicamente }\end{array}$ & 8,51 & 1,686 & 0,172 & & & \\
\hline \multirow{2}{*}{$\begin{array}{l}\text { Eu acredito que o turismo } \\
\text { aumenta a poluição ambiental } \\
\text { na Praia da Pipa }\end{array}$} & Depende economicamente & 6,39 & 2,064 & 0,153 & \multirow[b]{2}{*}{$-3,301$} & \multirow[b]{2}{*}{177,063} & \multirow[b]{2}{*}{0,00100} \\
\hline & $\begin{array}{c}\text { Não depende } \\
\text { economicamente }\end{array}$ & 7,31 & 2,282 & 0,233 & & & \\
\hline \multirow{2}{*}{$\begin{array}{l}\text { Eu acredito que o turismo } \\
\text { aumenta os níveis de ruído na } \\
\text { Praia da Pipa }\end{array}$} & Depende economicamente & 6,36 & 1,893 & 0,140 & \multirow{2}{*}{$-3,386$} & \multirow{2}{*}{185,591} & \multirow{2}{*}{0,00100} \\
\hline & $\begin{array}{c}\text { Não depende } \\
\text { economicamente }\end{array}$ & 7,19 & 1,980 & 0,202 & & & \\
\hline
\end{tabular}

Fonte: Dados do estudo, 2016. 


\section{(3) ayplied towitign}

Volume 2, número 3, 2017, p. 37-64

Tabela 04: Apego da comunidade a Praia da Pipa/RN.

\begin{tabular}{|c|c|c|c|c|c|c|c|}
\hline Variável & $\begin{array}{l}\text { Dependência } \\
\text { econômica do } \\
\text { turismo }\end{array}$ & Média & $\begin{array}{l}\text { Desvio } \\
\text { padrão }\end{array}$ & $\begin{array}{c}\text { Erro } \\
\text { padrão } \\
\text { da } \\
\text { média }\end{array}$ & $\begin{array}{c}\text { Teste } \\
\mathbf{t}\end{array}$ & df & Sig. \\
\hline \multirow{2}{*}{$\begin{array}{l}\text { Eu prefiro viver } \\
\text { nessa } \\
\text { comunidade do } \\
\text { que em } \\
\text { qualquer outra }\end{array}$} & $\begin{array}{c}\text { Depende } \\
\text { economicamente }\end{array}$ & 8,55 & 1,653 & 0,122 & \multirow[b]{2}{*}{3,897} & \multirow[b]{2}{*}{137,599} & \multirow[b]{2}{*}{$<0,00001$} \\
\hline & $\begin{array}{c}\text { Não depende } \\
\text { economicamente }\end{array}$ & 7,43 & 2,562 & 0,261 & & & \\
\hline \multirow{2}{*}{$\begin{array}{l}\text { Eu me } \\
\text { identifico com } \\
\text { a vida levada } \\
\text { nessa } \\
\text { comunidade }\end{array}$} & $\begin{array}{c}\text { Depende } \\
\text { economicamente }\end{array}$ & 8,37 & 1,618 & 0,120 & \multirow[b]{2}{*}{3,329} & \multirow[b]{2}{*}{136,628} & \multirow[b]{2}{*}{0,00100} \\
\hline & $\begin{array}{c}\text { Não depende } \\
\text { economicamente }\end{array}$ & 7,42 & 2,537 & 0,259 & & & \\
\hline \multirow{2}{*}{$\begin{array}{l}\text { Eu sinto que } \\
\text { essa } \\
\text { comunidade é } \\
\text { parte de mim }\end{array}$} & $\begin{array}{c}\text { Depende } \\
\text { economicamente }\end{array}$ & 8,66 & 1,440 & 0,106 & \multirow{2}{*}{4,028} & \multirow{2}{*}{141,326} & \multirow{2}{*}{$<0,00001$} \\
\hline & $\begin{array}{c}\text { Não depende } \\
\text { economicamente }\end{array}$ & 7,68 & 2,140 & 0,218 & & & \\
\hline \multirow{2}{*}{$\begin{array}{l}\text { Viver nessa } \\
\text { comunidade } \\
\text { diz muito sobre } \\
\text { quem eu sou }\end{array}$} & $\begin{array}{c}\text { Depende } \\
\text { economicamente }\end{array}$ & 8,42 & 1,535 & 0,113 & \multirow{2}{*}{3,746} & \multirow{2}{*}{130,115} & \multirow{2}{*}{$<0,00001$} \\
\hline & $\begin{array}{c}\text { Não depende } \\
\text { economicamente }\end{array}$ & 7,33 & 2,618 & 0,267 & & & \\
\hline \multirow{2}{*}{$\begin{array}{l}\text { Viver nessa } \\
\text { comunidade } \\
\text { significa muito } \\
\text { para mim }\end{array}$} & $\begin{array}{c}\text { Depende } \\
\text { economicamente }\end{array}$ & 8,61 & 1,547 & 0,114 & \multirow{2}{*}{3,386} & \multirow{2}{*}{145,804} & \multirow{2}{*}{0,00100} \\
\hline & $\begin{array}{c}\text { Não depende } \\
\text { economicamente }\end{array}$ & 7,76 & 2,194 & 0,224 & & & \\
\hline \multirow{2}{*}{$\begin{array}{l}\text { Eu sou muito } \\
\text { apegado a essa } \\
\text { comunidade }\end{array}$} & $\begin{array}{c}\text { Depende } \\
\text { economicamente }\end{array}$ & 8,66 & 1,485 & 0,110 & \multirow{2}{*}{3,074} & \multirow{2}{*}{139,796} & \multirow{2}{*}{0,00300} \\
\hline & $\begin{array}{c}\text { Não depende } \\
\text { economicamente }\end{array}$ & 7,88 & 2,244 & 0,229 & & & \\
\hline \multirow{2}{*}{$\begin{array}{l}\text { Eu sinto } \\
\text { fortemente } \\
\text { que pertenço a } \\
\text { essa } \\
\text { comunidade }\end{array}$} & $\begin{array}{c}\text { Depende } \\
\text { economicamente }\end{array}$ & 8,82 & 1,499 & 0,111 & \multirow[b]{2}{*}{4,105} & \multirow[b]{2}{*}{142,504} & \multirow[b]{2}{*}{$<0,00001$} \\
\hline & $\begin{array}{c}\text { Não depende } \\
\text { economicamente }\end{array}$ & 7,79 & 2,200 & 0,225 & & & \\
\hline
\end{tabular}

Fonte: Dados do estudo, 2016.

Como dito, a diferença do apego demostrado pelos dois grupos estudados é estatisticamente significativa em todas as variáveis observadas, sig. Inferior a 0,05. Além disso, é possível afirmar que a parcela dos residentes que dependem economicamente do turismo demostra maior apego a comunidade que aqueles ausentes das práticas produtivas do setor. É provável que esta tendência de comportamento seja influenciada pela relação 


\section{(0) \\ applied towigign}

Volume 2, número 3, 2017, p. 37-64

de dependência econômica por parte da população que está inserida diretamente no setor, tendendo a estimular maior apego destes residentes a comunidade a que pertencem.

Apoio da comunidade local ao desenvolvimento turístico

Por último, o estudo buscou analisar se havia diferença entre o nível de apoio ao desenvolvimento turístico dado por cada parcela da comunidade local estudada. Para isso, foram estipuladas 06 variáveis para avaliação por parte dos residentes. A tabela 05 resume as variáveis e seus resultados associados.

Tabela 05: Apoio da comunidade local ao desenvolvimento turístico

\begin{tabular}{|c|c|c|c|c|c|c|c|}
\hline Variável & $\begin{array}{l}\text { Dependência } \\
\text { econômica do } \\
\text { turismo }\end{array}$ & Média & $\begin{array}{l}\text { Desvio } \\
\text { padrão }\end{array}$ & $\begin{array}{c}\text { Erro } \\
\text { padrão } \\
\text { da } \\
\text { média }\end{array}$ & $\begin{array}{c}\text { Teste } \\
\mathbf{t}\end{array}$ & df & Sig. \\
\hline \multirow{2}{*}{$\begin{array}{l}\text { Eu apoio o } \\
\text { desenvolvimento } \\
\text { turístico da } \\
\text { comunidade }\end{array}$} & $\begin{array}{c}\text { Depende } \\
\text { economicamente }\end{array}$ & 8,78 & 2,102 & 0,155 & \multirow{2}{*}{5,471} & \multirow{2}{*}{139,388} & \multirow[b]{2}{*}{$<0,00001$} \\
\hline & $\begin{array}{c}\text { Não depende } \\
\text { economicamente }\end{array}$ & 6,80 & 3,191 & 0,326 & & & \\
\hline \multirow{2}{*}{$\begin{array}{l}\text { Eu acredito que o } \\
\text { município } \\
\text { deveria investir } \\
\text { mais na } \\
\text { promoção do } \\
\text { turismo em Pipa }\end{array}$} & $\begin{array}{c}\text { Depende } \\
\text { economicamente }\end{array}$ & 8,89 & 1,997 & 0,148 & \multirow[b]{2}{*}{5,137} & \multirow[b]{2}{*}{132,881} & \multirow[b]{2}{*}{$<0,00001$} \\
\hline & $\begin{array}{c}\text { Não depende } \\
\text { economicamente }\end{array}$ & 7,01 & 3,282 & 0,335 & & & \\
\hline \multirow{2}{*}{$\begin{array}{l}\text { Eu sou a favor do } \\
\text { estímulo ao } \\
\text { aumento do } \\
\text { número de } \\
\text { visitante em Pipa }\end{array}$} & $\begin{array}{c}\text { Depende } \\
\text { economicamente }\end{array}$ & 8,50 & 2,236 & 0,165 & \multirow[b]{2}{*}{4,680} & \multirow[b]{2}{*}{137,662} & \multirow[b]{2}{*}{$<0,00001$} \\
\hline & $\begin{array}{c}\text { Não depende } \\
\text { economicamente }\end{array}$ & 6,68 & 3,463 & 0,353 & & & \\
\hline \multirow{2}{*}{$\begin{array}{l}\text { Eu acredito que } \\
\text { Pipa está melhor } \\
\text { depois do } \\
\text { desenvolvimento } \\
\text { turístico do } \\
\text { município }\end{array}$} & $\begin{array}{c}\text { Depende } \\
\text { economicamente }\end{array}$ & 8,75 & 2,070 & 0,153 & \multirow[b]{2}{*}{4,684} & \multirow[b]{2}{*}{132,996} & \multirow[b]{2}{*}{$<0,00001$} \\
\hline & $\begin{array}{c}\text { Não depende } \\
\text { economicamente }\end{array}$ & 6,98 & 3,397 & 0,347 & & & \\
\hline \multirow{2}{*}{$\begin{array}{l}\text { Eu acredito que o } \\
\text { desenvolvimento } \\
\text { do turismo é } \\
\text { bastante } \\
\text { importante para } \\
\text { a comunidade } \\
\text { local de Pipa }\end{array}$} & $\begin{array}{c}\text { Depende } \\
\text { economicamente }\end{array}$ & 8,68 & 2,120 & 0,157 & \multirow[b]{2}{*}{5,159} & \multirow[b]{2}{*}{138,592} & \multirow[b]{2}{*}{$<0,00001$} \\
\hline & $\begin{array}{c}\text { Não depende } \\
\text { economicamente }\end{array}$ & 6,79 & 3,247 & 0,331 & & & \\
\hline
\end{tabular}




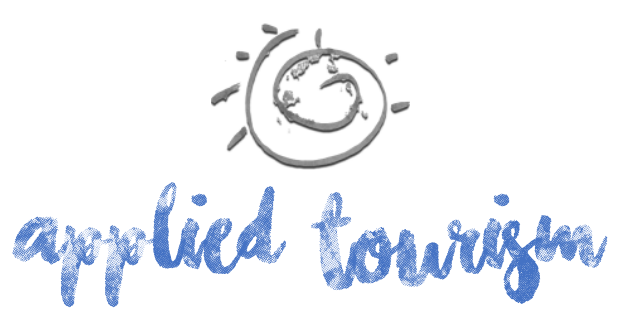

Volume 2, número 3, 2017, p. 37-64

\begin{tabular}{|l|c|c|c|c|c|c|c|}
\hline $\begin{array}{l}\text { Eu acredito que } \\
\text { desenvolver o } \\
\text { turismo em Pipa } \\
\text { é tão importante } \\
\text { quanto investir } \\
\text { na Saúde e } \\
\begin{array}{l}\text { Educação da } \\
\text { população }\end{array}\end{array}$ & $\begin{array}{c}\text { Depende } \\
\text { economicamente }\end{array}$ & 2,45 & 1,425 & 0,105 & & & \\
economicamente depende & 2,44 & 1,672 & 0,171 & 0,080 & 168,375 & 0,93600 \\
\hline
\end{tabular}

Fonte: Dados do estudo, 2016.

Da tabela 05 , foi possível concluir que a intenção de apoiar o desenvolvimento turístico local, por parte da comunidade, é mais elevada, naturalmente, entre o grupo de residentes que depende economicamente da atividade turística. Este resultado demonstra forte indicativo que o fato de depender economicamente da atividade turística pode influenciar de forma expressiva o apoio que o residente destina ao desenvolvimento turístico local. Cabe destacar também que as diferenças entre os níveis de apoio dos grupos de residentes estudados são estatisticamente significativas, ou seja, sig. inferior a 0,05 como já indicando anteriormente, com exceção de uma variável.

Quando analisado o desvio padrão dos resultados, é possível notar que esta dimensão apresenta, de um modo geral, os maiores valores de desvio padrão dentre todas as dimensões estudadas. Este resultado demonstra significativa variação entre percepções da parcela de residentes que não trabalha com o turismo sobre o apoio destinado ao desenvolvimento da atividade turística. Essa constatação conduz a análise a inferir que dentro da parcela de moradores, que não dependem do turismo, há uma relativa dispersão dos níveis de apoio ao desenvolvimento turístico local. Desse modo, faz-se mister destacar as hipóteses confirmadas pelo estudo, conforme Quadro 02. 


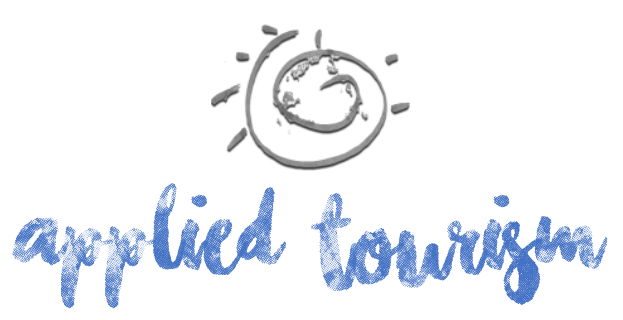

Volume 2, número 3, 2017, p. 37-64

QUADRO 02: Resultados das Hipóteses do estudo.

\begin{tabular}{|c|c|c|}
\hline \multicolumn{2}{|r|}{ Hipóteses do Estudo } & \multirow{2}{*}{$\begin{array}{c}\begin{array}{c}\text { Validação das } \\
\text { Hipóteses }\end{array} \\
\begin{array}{c}\text { Não rejeitada } \\
\text { (confirmada) }\end{array}\end{array}$} \\
\hline$H 1$ & $\begin{array}{l}\text { Os residentes com dependência econômica do turismo possuem percepção da } \\
\text { imagem do lugar superior àqueles que não possuem dependência }\end{array}$ & \\
\hline$H 2$ & $\begin{array}{l}\text { Os residentes com dependência econômica do turismo possuem percepção } \\
\text { sobre os impactos positivos do turismo mais favorável que àqueles que não } \\
\text { possuem dependência }\end{array}$ & $\begin{array}{l}\text { Não rejeitada } \\
\text { (confirmada) }\end{array}$ \\
\hline H3 & $\begin{array}{l}\text { Os residentes com dependência econômica do turismo possuem percepção } \\
\text { sobre os impactos negativos do turismo mais atenuada que àqueles que não } \\
\text { possuem dependência }\end{array}$ & $\begin{array}{l}\text { Não rejeitada } \\
\text { (confirmada) }\end{array}$ \\
\hline$H 4$ & $\begin{array}{l}\text { Os residentes com dependência econômica do turismo demonstram maior } \\
\text { sentimento de apego à comunidade se comparados àqueles que não possuem } \\
\text { dependência }\end{array}$ & $\begin{array}{l}\text { Não rejeitada } \\
\text { (confirmada) }\end{array}$ \\
\hline H5 & $\begin{array}{l}\text { Os residentes com dependência econômica do turismo demonstram maior } \\
\text { tendência de apoiar o desenvolvimento da atividade turística se comparados } \\
\text { àqueles que não possuem dependência }\end{array}$ & $\begin{array}{l}\text { Não rejeitada } \\
\text { (confirmada) }\end{array}$ \\
\hline
\end{tabular}

Fonte: Dados do estudo, 2016.

Conforme Quadro 02, é possível concluir, de um modo geral, que todas as hipóteses foram confirmadas.

\section{IMPLICAÇÕES TEÓRICAS E GERENCIAIS}

Dos resultados encontrados, é possível destacar significativas contribuições, do ponto de vista teórico e prático, e desdobramentos para fins de planejamento e gestão de stakebolders em destinações turísticas.

Do ponto de vista teórico, faz-se mister destacar que a dependência econômica da atividade turística é um fator fortemente relevante para a explicação da percepção da comunidade autóctone sobre o turismo, quando analisadas as dimensões estudadas, a saber: imagem, impactos positivos e negativos, apego e apoio da comunidade. Este resultado, corroborado pela vasta literatura discutida no estudo, expõe interessantes implicações sobre o tema, como o efeito que a esfera econômica da dependência tem sobre o comportamento e percepções dos sujeitos que residem em comunidades com a presença da atividade 


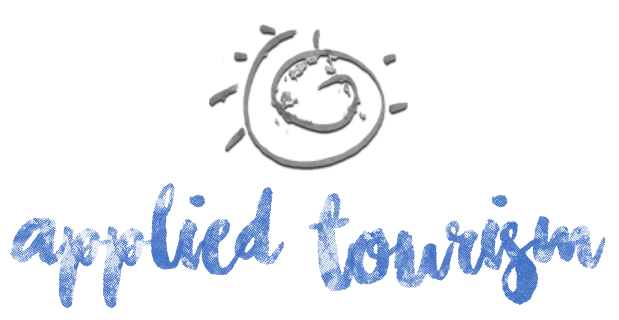

Volume 2, número 3, 2017, p. 37-64

opiniões sobre o apoio ao desenvolvimento turístico no grupo que não depende economicamente do setor de turismo.

Com base nos resultados, observou-se necessidade de se desenvolver por meio do poder público, e também privado, políticas e projetos de sensibilização sobre o desenvolvimento da atividade turística. Desse modo, objetivando, doravante, gerenciar de forma mais adequada a percepção dos residentes locais quanto aos impactos do setor, como também desenvolver campanhas que estimulem o apoio do residente ao turismo, sua relação de apego com a comunidade e melhoria da imagem do próprio lugar.

\section{REFERÊNCIAS}

Almeida, M. G. S. (2013). Uma análise da relação entre apego ao lugar, satisfação e fidelidade dos visitantes em um destino turístico ambiental: Um estudo em Fernando de Noronha/PE. (Dissertação Mestrado em Turismo) - Universidade Federal do Rio Grade do Norte, Natal.

Andereck, K.L., \& Nyaupane, G.P. (2011). Exploring the nature of tourism and quality of life perceptions among residents. Journal of Travel Research, 50(3), p. 248-260.

Andreck, K.L., \& Valentine, K.M., Knopf, R.C., Vogt, C.A. (2005). Residents' perceptions of community tourism impacts. Annals of Tourism Research, 32(4), p. 1056-1076.

Baloglu, S., \& Mccleary, K. W. (1999). A model of destination image formation. Annals of Tourism Research. 26(4), p. 868-897.

Bujosa, A., \& Rosselló, J. (2007). Modelling environmental attitudes toward tourism. Tourism Management, 28(3), p. 688-695.

Besculides, A., Lee, M.E., \& McCormick, P.J. (2002). Residents' perceptions of the cultural benefits of tourism. Annals of Tourism Research, 29(2), p. 303-319.

Brunt, P. \& Courtney, P. (1999). Host perceptions of sociocultural impacts. Annals of Tourism Research, 26(3), p. 493-515.

Brandão, C. N., Barbieri, J. C., \& Silva, L. C. J. (2012). Turismo sustentável em comunidades indígenas da Amazônia. Revista de Administração de Roraima: RARR, 12(2), p.1-12.

Chagas, M. M. (2008). Imagem de destinos turísticos: uma discussão teórica da literatura especializada. Revista Turismo Visão e Ação, 10(3), p. 435 - 455.

Chagas, M. M., Silva, M. A., Silva, V. H., \& Marques Júnior, S. (2016a). Classificação de residentes em relação ao apoio para o desenvolvimento turístico em comunidades indígenas: Uma 


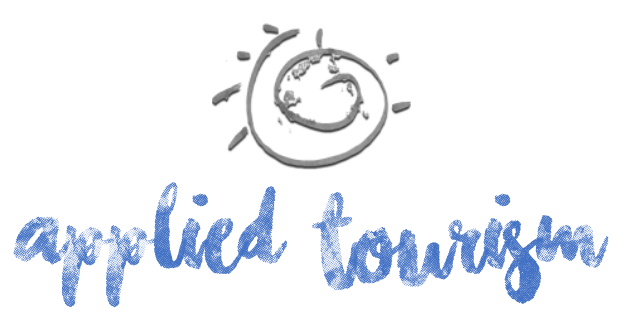

Volume 2, número 3, 2017, p. 37-64

tipologia empirica baseada em Cluster Analysis. In: anais do X Fórum Internacional de Turismo do Iguassu, Paraná, PR.

Chagas, M. M., Marques Júnior, S., \& Silva, V. H. (2016b). Imagem de destinos turísticos: Conceitos, modelos e casos. Natal, RN: Editora do IFRN.

Corrar, L. J., Paulo, E., \& Dias Filho, J. M. (2007). Análise multivariada: Para cursos de administração, ciências contábeis e economia. São Paulo, SP: Atlas.

Dyer, P., Gursoy, D., Sharma, B., Carter, J. (2007). Structural modeling of resident perceptions of tourism and associated development on the Sunshine Coast, Australia. Tourism Management, 28(2), p. 409-422.

Funk, D. C., \& James, J. D. (2006). Consumer loyalty: The meaning of attachment in the development of sport team allegiance. Journal of Sport Management, 20 (2), p. 189-217.

Gursoy, D., \& Kendall, K.W. (2006). Hosting mega events e modeling locals support. Annals of Tourism Research. 33(3), p. 603-623.

Gursoy, D., Jurowski, D., \& Uysal, M. (2002). Resident Attitudes: A Structural Modeling Approach. Annals of Tourism Research. 29(1), p. 79-105.

Gursoy, D, \& Rutherford, D.G. (2004). Host attitudes toward tourism: An improved structural model. Annals of Tourism Research, 31(3), p. 495-516.

Haley, A.J., Snaith, T., \& Miller, G. (2005). The social impacts of tourism: A case study of Bath, UK. Annals of Tourism Research, 32(3), 647-668.

Haralambopoulos, N., \& Pizam, A. (1996). Perceived impacts of tourism: The case of Samos. Annals of Tourism Research, 23(3), p. 503-526.

Hair Júnior, J. F., Black, W. C., Babin, B. J., Anderson, R. E., \& Tatham, R. L. (2009). Análise multivariada de dados. 6. ed. Porto Alegre: Bookman.

Jones, S. (2005). Community-based ecotourism: the significance of social capital. Annals of Tourism Research, 32(2), p. 303-324.

Jurowski, C., Uysal, M., \& Williams, R (1997). A Theoretical Analysis of Host Community Resident Reactions to Tourism. Journal of Travel Research, 36(2), p. 3-11.

Kaltenborn, B. P., Andrsen, O., Nellemann, C., Bjerke, T., \& Thrane, C. (2008). Resident attitudes towards mountain second-home tourism development in Norway: The effects of environmental attitudes. Journal of Sustainable Tourism, 16(6), p. 664-680.

Korca, P. (1996). Resident attitudes toward tourism impacts. Annals of Tourism Research, 23(3), p. 695-726.

Lepp, A. (2007). Residents' attitudes towards tourism in Bigodi village, Uganda. Tourism Management, 28(3), p. 876-885. 


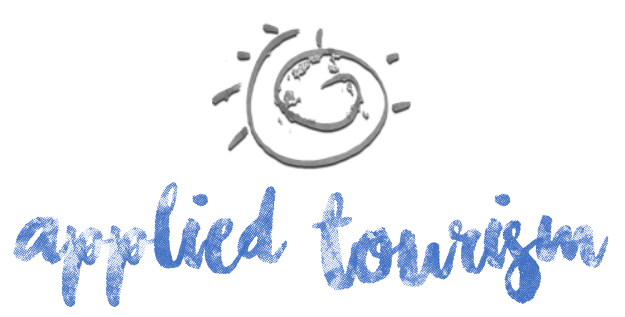

Volume 2, número 3, 2017, p. 37-64

Silva, G. B. (2014). Fatores capazes de influenciar o apoio dos residentes ao desenvolvimento do turismo religioso em Santa Cruz - $R N$. (Dissertação Mestrado em Turismo). Universidade Federal do Rio Grande do Norte, Natal.

Silva, M. A. A., Silva, M. N., \& Chagas, M. M. (2015). Apoio dos residentes ao desenvolvimento do turismo em comunidades indígenas: um estudo no Catu dos Eleutérios. In: anais do X Congresso Norte Nordeste de Pesquisa e Inovação, Acre (AC).

Silva, V. H., \& Chagas, M. M. (2016a). Análise da relação entre perfil sociodemográfico da comunidade local e o grau de apoio ao desenvolvimento da atividade turística, In: anais do XII Seminário da Associação Brasileira de Pós-graduação em Turismo (ANPTUR), São Paulo (SP).

Silva, V. H., \& Chagas, M. M., Marques Júnior, S. (2016b). Classificação de residentes em relação ao apoio para o desenvolvimento de destinos turísticos costeiros, In: anais do XII Seminário da Associação Brasileira de Pós-graduação em Turismo (ANPTUR), São Paulo, SP.

Thomson, M., Macinnis, D. J., \& Park, C. W. (2005). The ties that bind: measuring the strength of consumers' emotional attachments to brands. Journal of Consumer Psychology, 15(1), p. 77-91.

Um, S., \& Crompton, L. (1987). Measuring resident's attachment levels in a host community. Journal of Travel Research, v. 26(2) p. 27-29.

Vieira, K. F. (2014). Avaliação do apoio dos residentes no processo de gestão de projetos turísticos ambientais: Um estudo do vale dos dinossauros - Sousa/PB. (Dissertação de Mestrado em Turismo). Universidade Federal do Rio Grande do Norte, Natal.

Yoon, Y., Gursoy, D., \& Chen, J. S. (2001). Validating a tourism development theory with structural equation modeling. Tourism Management, v. 22, p. 363-372, 2001.

Yuksel, A. B., Yuksel, F., \& Bilim, Y. (2010). Destination attachment: Effects on customer satisfaction and cognitive, affective and conative loyalty. Tourism Management, 31(2), p. 274-284. 